\title{
PAPER
}

\section{Muscle fibrillin deficiency in Marfan's syndrome myopathy}

\author{
W M H Behan, C Longman, R K H Petty, P Comeglio, A H Child, M Boxer, P Foskett, \\ D G F Harriman
}

See end of article for authors' affiliations

......................

Correspondence to: Professor W M H Behan,

Department of Pathology, Western Infirmary,

Glasgow G11 6NT, UK;

wmblq@clinmed.gla.ac.uk

Received 29 August 2002

In revised form

10 December 2002

Accepted

11 December 2002

\begin{abstract}
Objective: To report a family with Marfan's syndrome in whom a myopathy was associated with respiratory failure; muscle biopsies from affected individuals were examined to determine whether there were abnormalities in fibrillin.

Methods: 21 family members underwent detailed clinical examination, including neurological and pulmonary assessment. Muscle biopsies in the most severely affected cases were immunostained using monoclonal antibodies to specific fibrillin components. Genomic DNA from all 21 members was analysed for mutations in the fibrillin gene, FBN1, on 15q21.

Results: 13 individuals had a C4621T base change in exon 37 of the FBN1 gene, which in four cases segregated with muscle weakness or evidence of respiratory muscle dysfunction or both. Their muscle biopsies revealed an abnormality in fibrillin immunoreactivity.

Conclusions: Abnormalities in fibrillin can be detected in muscle biopsies from patients with Marfan's syndrome who have myopathy. This pedigree, with a point mutation in FBN1, also draws attention to the potential for respiratory failure associated with myopathy.
\end{abstract}

M arfan's syndrome is the commonest autosomal dominant inherited disorder of connective tissue, with a prevalence of $1 / 5000$ to $1 / 10000$ individuals. ${ }^{12}$ There is complete penetrance but great variability in phenotype, the latter varying from florid abnormalities to just outside normal limits. ${ }^{34}$

The diagnostic criteria have been established in two workshops as major features in the ocular, cardiovascular, and skeletal systems associated with involvement of the lungs and integument. ${ }^{5}$ Dural ectasia may be the most sensitive clinical diagnostic marker but its specificity remains to be

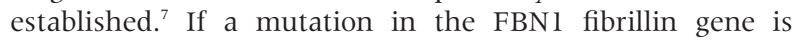
detected, then a major criterion in an organ system and the involvement of another is diagnostic; for relatives, a positive family history, one major criterion, and involvement of a second organ system meet the criteria. ${ }^{5}$ The skeletal anomalies which raise the possibility of Marfan's syndrome are quite common in the general population and have necessitated the establishment of rigid guidelines.

Poor muscle development was commented on by Marfan in his original description of an affected five year old child. ${ }^{8}$ Although then considered part of the symptom complex, ${ }^{9-11}$ it was poorly characterised and myopathy is not mentioned in the most widely quoted review article ${ }^{3}$ or in the two international workshops. ${ }^{56}$

Fibrillin-1, the $350 \mathrm{kDa}$ glycoprotein involved in Marfan's syndrome, is present in the endomysium and perimysium of skeletal muscles. ${ }^{12-14}$ It is widely distributed in the body, where it forms a major component of the microfibrillar system and contributes to the mechanical properties of elastic fibres. ${ }^{12} 1315$ Mutations in the FBNl gene on chromosome 15q21 which encodes fibrillin-1 are associated with cases of Marfan's syndrome. ${ }^{16}$ Mutations in the FBN2 gene give rise to clinical syndromes (fibrillinopathies) which show phenotypic overlap with Marfan's syndrome, ${ }^{12}$ while on the other hand one family with Marfan's syndrome has been linked to a locus on chromosome 3p. ${ }^{17}$ Thus the diagnosis of Marfan's syndrome has remained a clinical one.

We report a family fulfilling the diagnostic criteria but also having muscle weakness associated with respiratory failure and abnormal fibrillin immunoreactivity in the endomysium and perimysium.

\section{METHODS}

Needle muscle biopsy specimens were obtained from the vastus lateralis muscle of three cases $(11: 7,11: 4,111: 3)$ using a modified Arthrodax needle (Oxylitre, Edinburgh, Scotland) as described. ${ }^{18}$ Frozen sections of $5 \mu \mathrm{m}$ thickness were examined using the following stains in the order given: haematoxylin and eosin, modified Gomori trichrome, adenosine triphosphatase at pH 9.4 and 4.3, NADH-tetrazolium reductase, succinate dehydrogenase, cytochrome oxidase, oil red O, PAS, PAS with diastase, and acid phosphatase. Stains for myophosphorylase (MP), phosphofructokinase (PFK), and myoadenylate deaminase (AMP) were included. ${ }^{18}$ Appropriate controls were used in sequence. Antibodies to dystrophins (C terminal, $\mathrm{N}$ terminal, and rod domains), $\alpha, \beta, \gamma$, and $\delta$ sarcoglycans, emerin, and merosin were used in a standard immunohistochemical protocol. ${ }^{19}$ For electron microscopic examination, the specimens were left at $4^{\circ} \mathrm{C}$ overnight, processed, and examined in a Philips CM10 electron microscope. ${ }^{18}$

\section{Fibrillin studies}

The following commercially available mouse monoclonal antibodies to human fibrillin (Chemicon International, Harrow, Middlesex, UK) were used: MAB 1919 to fibrillin, MAB 2499 to fibrillin-1, C terminal, and MAB 2502 to fibrillin-1, N terminal. The optimum dilutions for the antibodies were established as 1:200 for MAB 1919 and MAB 2499, and 1:1500 for MAB 2502, with all incubations being for one hour at room temperature. Visualisation was obtained using avidin-biotin complex in the Vector Elite kit. ${ }^{19}$

\section{CASE DESCRIPTIONS}

Diagnosis of Marfan's syndrome in each case was based on the strict clinical guidelines. ${ }^{56}$ Written informed consent to include their data was obtained from all family members except for II:8 and III:1, who declined assessment. 
Table 1 Details of affected individuals

\begin{tabular}{|c|c|c|c|c|c|c|c|c|c|c|c|c|c|}
\hline \multirow[b]{2}{*}{ Feature } & \multicolumn{13}{|c|}{ Proband } \\
\hline & II-1 & II-2 & II-4 & II-5 & II-6 & II-7 & III-3 & III-6 & III-7 & III-8 & III-9 & III-10 & III-11 \\
\hline Age (years) & 48 & 42 & 46 & 45 & 40 & 38 & 20 & 13 & 21 & 26 & 20 & 17 & 14 \\
\hline FBN1 mutation & + & + & + & + & + & + & + & + & + & + & + & + & + \\
\hline Span:height >1.05 & + & - & - & - & - & - & - & - & - & - & - & - & - \\
\hline Wrist/thumb sign & - & + & + & + & - & + & + & + & + & - & - & + & - \\
\hline Pectus carinatum & - & + & + & + & + & + & + & + & + & + & + & + & + \\
\hline Pectus excavatum & - & - & - & - & - & - & - & - & - & - & - & - & - \\
\hline Scoliosis & - & - & + & - & - & + & - & - & - & - & - & - & - \\
\hline Pes planus & - & - & - & - & - & - & - & - & - & - & - & - & - \\
\hline Acetabular protrusion & nt & $\mathrm{nt}$ & - & $\mathrm{nt}$ & $\mathrm{nt}$ & - & $\mathrm{nt}$ & nt & $\mathrm{nt}$ & $\mathrm{nt}$ & $\mathrm{nt}$ & - & $\mathrm{nt}$ \\
\hline Reduced elbow extension & - & - & - & - & - & - & - & - & - & - & - & - & - \\
\hline Marfanoid facies & - & + & + & + & + & + & + & + & + & + & + & + & + \\
\hline High arched palate & - & + & + & + & + & + & + & + & + & + & + & + & + \\
\hline Joint hypermobility & - & - & - & - & - & - & + & + & - & - & - & - & - \\
\hline Mitral prolapse/regurgitation & + & nt & - & + & - & + & + & - & - & - & - & - & - \\
\hline Aortic dilatation & + & nt & - & - & - & - & - & - & - & - & - & + & - \\
\hline Recurrent pneumothorax & - & - & + & - & - & - & - & - & - & - & - & - & - \\
\hline Skin striae & - & - & - & - & - & - & + & - & + & + & + & - & + \\
\hline Recurrent hernias & - & + & - & - & - & - & + & - & - & - & - & + & - \\
\hline Ectopia lentis & $\mathrm{nt}$ & $\mathrm{nt}$ & - & - & - & - & - & - & - & - & - & - & - \\
\hline Myopia & - & - & - & - & - & - & + & - & - & - & - & + & - \\
\hline Dural extasia & $\mathrm{nt}$ & $\mathrm{nt}$ & $\mathrm{nt}$ & nt & nt & $\mathrm{nt}$ & $\mathrm{nt}$ & $\mathrm{nt}$ & nt & $\mathrm{nt}$ & $\mathrm{nt}$ & $\mathrm{nt}$ & $\mathrm{nt}$ \\
\hline Limb weakness & - & - & - & - & - & + & + & - & - & - & - & - & - \\
\hline Respiratory weakness & - & $\mathrm{nt}$ & + & - & - & + & - & + & - & - & - & - & - \\
\hline
\end{tabular}

\section{Case 1, proband II:7}

This woman underwent mitral valve replacement aged 18 years, subsequently developing left atrial enlargement and atrial fibrillation with pulmonary hypertension. She was treated with digoxin and warfarin and remained well, working as a full time secretary, until her emergency admission at the age of 37 years with a deteriorating level of consciousness following a two day history of fever and cough. A diagnosis was made of type II respiratory failure secondary to bronchopneumonia and she was intubated and ventilated. She was slow to wean from the ventilator because of poor respiratory effort.

Nerve conduction studies, late response tests, and needle electromyography (EMG) were applied appropriately for the clinical symptoms and signs. Repetitive stimulation studies of the right ulnar nerve were normal. Motor and sensory nerve conduction studies were normal for velocity and latency, although the computed motor action potential (CMAP) was very small in each location. The F waves were absent. Needle EMG did not show any active membrane disturbance but the universal overall pattern was of very tiny, short duration, triphasic motor unit potentials. The findings suggested an end stage congenital myopathy/dystrophy. Muscle biopsy was done (see below). Mutation analysis for myotonic dystrophy showed a repeat size within normal limits and her karyotype was normal $(46, \mathrm{XX})$.

She was discharged home receiving nocturnal non-invasive respiratory support (BI PAP). She is easily fatigued and has not returned to work but is independent in tasks of daily living including walking around her local shopping centre. She has an asthenic build with severe axial weakness, plus mild proximal and distal limb weakness. Tendon reflexes are intact and plantar responses flexor. Respiratory assessment revealed evidence of severe respiratory muscle weakness. Sitting vital capacity was 0.65 litres, inspiratory mouth pressure reduced at $36 \mathrm{~cm} \mathrm{H}_{2} \mathrm{O}$ (normal $>70$ ), and expiratory mouth pressure reduced at 59 $\mathrm{cm} \mathrm{H}_{2} \mathrm{O}$ (normal >90). She is unable to lie flat because of shortness of breath consistent with diaphragmatic weakness. The remaining clinical features are shown in table 1.

\section{Case 2, proband II.4}

This women, aged 46 years, was a poor athlete with easy fatiguability since childhood but is not limited in her daily living activities. She has an asthenic build with poor muscle bulk but no muscle weakness. She has minor pectus carinatum. Pulmonary function tests revealed evidence of mild respiratory muscle weakness: $\mathrm{FEV}_{1}$ was 2.07 litres ( $71 \%$ of predicted), and FVC, 2.14 litres (64\% of predicted). Inspiratory mouth pressure was $62 \mathrm{~cm} \mathrm{H}_{2} \mathrm{O}$ (normal > 70) and expiratory mouth pressure $71 \mathrm{~cm} \mathrm{H}_{2} \mathrm{O}$ (normal > 90). These measurements have remained stable for the past year. A muscle biopsy was done (see below).

\section{Case 3, proband III:3}

This woman, aged 20 years, has had lifelong exertional dyspnoea on moderate exertion, for example when running, but is able to participate in kick boxing classes. On examination, she had mild lower limb weakness with some difficulty rising on heels and toes and she was slow to rise from a squat. A muscle biopsy was done (see below). Pulmonary function tests were normal, including lying and standing $\mathrm{FEV}_{1}$ and FVC and mouth pressures.

\section{Case 4, proband III:6}

This boy has mild pectus carinatum. He did not describe muscle or respiratory symptoms, and had no muscle weakness on clinical examination but, aged 13 years, initial spirometry was abnormal with an $\mathrm{FEV}_{1}$ of 2.6 litres (57\% of predicted) and an FVC of 2.64 litres (60\% of predicted). Aged 14 years, his results remained abnormal with FEV, 3.59 litres and FVC 3.72 litres. Peak inspiratory and expiratory pressures were within the normal range but the respiratory physician commented that his results were similar to those of his mother (case 2). Parental consent for muscle biopsy was refused.

\section{Other family members}

The clinical details are shown in table 1. Two of the 23 individuals declined assessment (II:8 and III:1). The remaining 21 each underwent a detailed clinical examination, including a neurological assessment of muscle function, slit lamp eye examination, echocardiogram, and evaluation of respiratory function with spirometry. Thirteen of the 21 had Marfan's syndrome and of these, three had evidence of muscle weakness and respiratory dysfunction (cases 1, 2, and 3) while a fourth (case 4 ) had evidence of respiratory muscle 


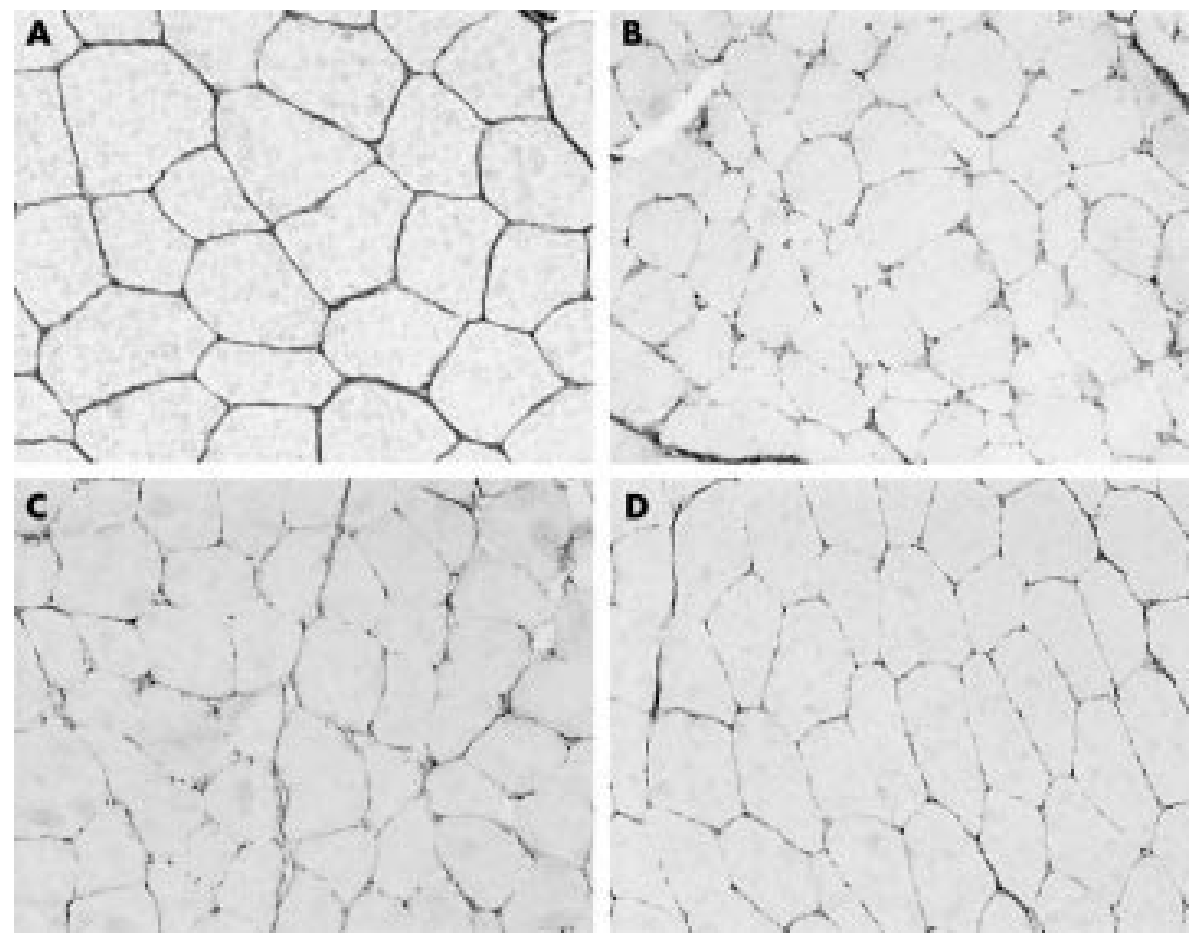

Figure 1 Demonstration of defective fibrillin distribution in three family members with myopathy and Marfan's syndrome. Frozen sections of muscle biopsies, immunostained to show human fibrillin, $\times 200$ : (A) normal control, (B) case 1, (C) case 2, (D) case 3. It can be seen that, compared with the control, fibrillin appears defective, wispy, and fragmented in the three cases.

dysfunction only. Eight individuals were unaffected, none complaining of muscle or respiratory symptoms and all with normal muscle power and spirometry tests.

\section{Muscle biopsy findings}

Case 1, proband II:7

Two biopsies were obtained from case 1, which were similar apart from moderate diffuse atrophy of type 2 fibres in the first biopsy, considered to reflect the period in the intensive care unit. The mean diameters of both fibre types were within nor- mal limits one month after discharge; a normal mosaic pattern was seen, with type 1 predominance (62\% v 38\%). No fibre necrosis, phagocytosis, inflammation, fibrosis, or ragged red fibres were present. Histochemical enzyme stains (SD, $\mathrm{NADH}$, and COX) were normal, although lysosomes were slightly more conspicuous, in keeping with muscle damage. AMP, MP, and PFK were present. The blood vessels were unremarkable. Immunohistochemical screening revealed normal staining for the dystrophin molecule, $\alpha, \beta, \gamma$, and $\delta$ sarcoglycans, laminin, merosin, and emerin and there was no
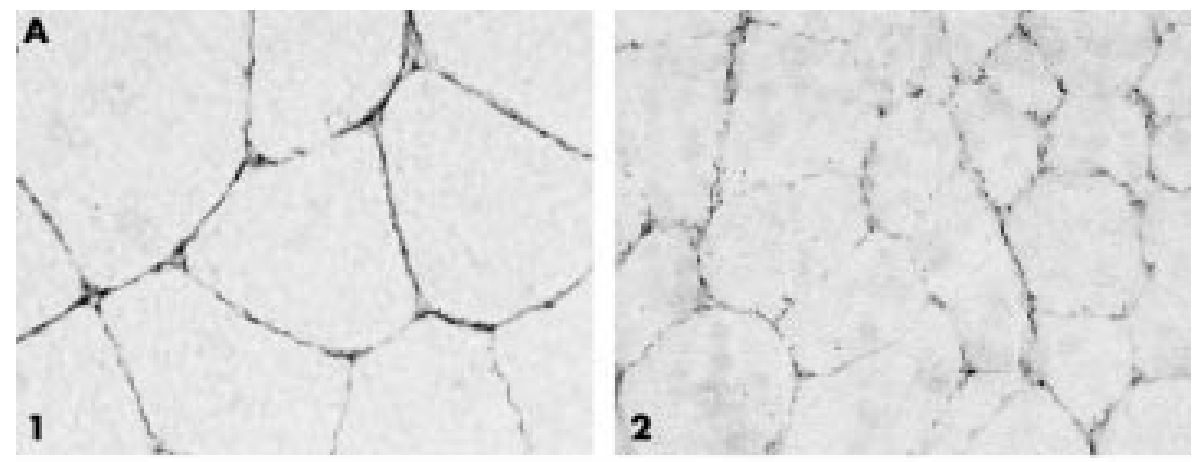

Figure 2 Demonstration of truncated fibrillin-1 protein $(\times 400)$.

Frozen sections of muscle biopsies immunostained with monoclonal antibodies to the C-terminal fragment (A) and the $\mathrm{N}$-terminal fragment (B). Compared with the normal control $(A)$ and $B 1)$, there is severe deficiency of the C-terminal fragment of fibrillin-1 (A2) but not of the $\mathrm{N}$-terminal fragment (B2).
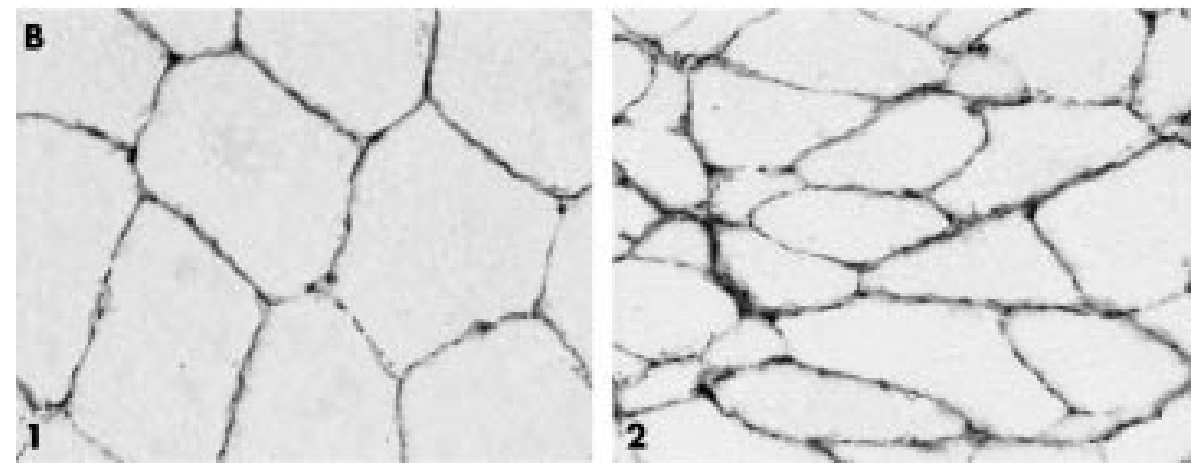


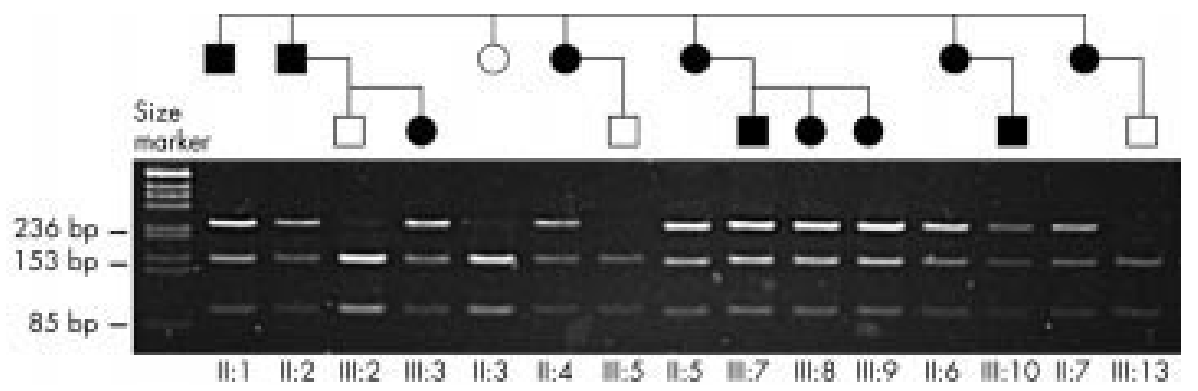

Figure 3 Polymerase chain reaction (PCR) and restriction enzyme digest of exon 37 of fibrillin-1. Unaffected individuals have bands at 153 base pairs (bp) and 85 bp corresponding to the products of restriction enzyme digest with Ava 1. The C4621T mutation abolishes this restriction site; thus affected individuals have an additional band at $236 \mathrm{bp}$ corresponding to the undigested PCR product of the mutant allele.

utrophin or fetal myosin positive fibres. Ultrastructural studies showed mild non-specific damage and a normal interstitium.

Immunohistochemical stains for human fibrillin (whole molecule) revealed a dramatic picture (fig 1). Compared with the control normal muscle (panel A) immunoreactivity for endomysial fibrillin was detectable only in a fragmented wispy form (panel B), completely absent in some peripheral areas. Perimysial fibrillin was similarly reduced to a thinner, more irregular line. In fig 2, the results with the specific antibodies to the N-terminal and C-terminal ends of the fibrillin- 1 protein are shown at a higher magnification: the specific antibody to the $\mathrm{C}$ terminal showed a severely reduced fibrillin in the patient (panel A2) compared with the control (panel Al), while the staining intensity with the antibody to the $\mathrm{N}$ terminal of fibrillin-1, although slightly irregular in its distribution (panel B2), was similar to that in the control (panel B1). These features are consistent with the presence of a truncated form of fibrillin.

\section{Case 2, proband II:4}

Microscopy revealed well formed muscle fascicles with type 1 and type 2 fibres (mean diameter $50 \mu \mathrm{m}$ ) in the usual mosaic pattern, with a predominance of type 2 fibres (80\% v 20\%) and no necrosis, phagocytosis, inflammation, fibrosis, or ragged red fibres. No abnormalities were detected in the histochemical or immunochemical stains and those on ultrastructure were mild and non-specific. Stains for fibrillin, however, revealed a picture similar to case 1 ( fig $1 C$ ), with evidence that the fibrillin deposited was reduced in amount and was in the truncated form (not shown).

\section{Case 3, proband III:3}

There was predominance of type l fibres (65\% v 35\%) but no other histological, histochemical, or ultrastructural abnormalities. Staining with antifibrillin antibodies (fig 1D), however, revealed similar features to cases 1 and 2 .

\section{Genetic studies}

Venous blood samples were collected from 11 of the 13 individuals with Marfan's syndrome and from four unaffected family members, as shown in fig 3, and genomic DNA was extracted using standard procedures.

Linked STS markers showed segregation of disease with a common haplotype at the fibrillin-1 locus at 15q21. ${ }^{20}{ }^{21}$ Single stranded conformational polymorphism (SSCP) screening of all exons of the fibrillin-1 gene identified a band shift in exon 37. Sequencing of exon 37 showed a heterozygotic substitution of nucleotide $462 \mathrm{l}$ from $\mathrm{C}$ to $\mathrm{T}(462 \mathrm{l} \mathrm{C} \rightarrow \mathrm{T})$. This introduces a premature Stop codon in place of arginine in position 154l (R1541X) in the domain TB \#04 of the fibrillin-1 protein.

The C462 1T mutation causes a loss of a wild-type restriction site for the enzyme Ava I. Polymerase chain reaction products of exon 37 from individuals in the pedigree were subjected to restriction digest by Ava I. Products were run on agarose gel and visualised by ethidium bromide staining. The undigested product is 236 base pairs (bp) in size and the digested products are $83 \mathrm{bp}$ and $153 \mathrm{bp}$. The mutation segregates with the phenotype in this family, being present in all 11 affected individuals and absent in all four unaffected individuals, as shown in fig 3.

\section{DISCUSSION}

This pedigree conforms to the diagnostic requirements of Marfan's syndrome: one individual (III.10) fulfils the clinical criteria completely (aortic root dilatation, involvement of the skeletal system and the integument) while the other affected individuals have multisystem disease associated with the same point mutation. In addition, some family members had a myopathy, affecting the respiratory muscles particularly, which segregated with the disease and with the mutation in the FBNl gene.

Muscle biopsies in three of these cases are consistent with the presence of a truncated form of fibrillin. The reason for the selective respiratory muscle involvement is not clear, but this is a feature of certain other muscle diseases, for example LGMD 2.I. Alternatively, tissue heterogeneity is well known to occur in Marfan's syndrome and could account for both this and the fact that other family members with the same mutation did not have myopathy.

Myopathy has not been regarded recently as a component of Marfan's syndrome, ${ }^{356}$ although poor muscle development and an asthenic build are well recognised. The slim weak muscles respond poorly to body building exercises (Child A, unpublished data). Marfan considered muscle involvement to be integral, with the small muscles "recalling atrophy". ${ }^{8}$ In subsequent reports, muscle hypoplasia was mentioned in up to $80 \%$ of cases $^{9}{ }^{10}$ or even in $100 \%$ in small series. "Muscular underdevelopment and hypotonia is a frequent but by no means invariable feature. This feature has been so striking as to suggest a primary disorder of muscle in some instances," as stated in McKusick's Heritable Disorders of Connective Tissues (1966). ${ }^{22}$

In refining the nosology of Marfan's syndrome in 1979, however, Pyeritz and McKusick did not mention myopathy. ${ }^{3}$ Nonetheless, cases with obvious muscle involvement continued to be reported..$^{23-32}$ Some may have been individuals with marfanoid features, ${ }^{23} 24282930$ but three were undoubtedly cases of Marfan's syndrome and in these the myopathic features were similar to ours, with the exception of respiratory muscle involvement. ${ }^{25-27}$ Electromyography confirmed the myopathic picture. Histological studies revealed "ringbinden" in two cases $^{25}{ }^{27}$ : concentric striated annulets of myofibrils surrounding central transversely oriented ones. These are considered to be evidence of a lack of appropriate tension on the muscle. Myofibrillar disarray may then occur and indeed this was identified in one case. ${ }^{25}$ Endomysium and perimysium were considered normal. The second $\operatorname{case}^{27}$ was reported as a centronuclear myopathy with fingerprint inclusion ${ }^{27}$ but this 
diagnosis has not been given in any other cases of Marfan's syndrome. The inclusions may have represented regeneration occurring with longstanding chronic damage, or disordered growth. In the third case, no abnormalities other than non-specific mild variation in type 1 fibre size were seen. ${ }^{26}$ Other possible cases reported had clinical details too scanty for analysis $^{32}$ or the muscle weakness was considered to be caused by an associated inherited peripheral neuropathy. ${ }^{31}$

Myopathy may be more frequent within the fibrillinopathies than previously recognised. A boy who presented at the age of eight years, possibly with Beal's syndrome-a fibrillinopathy associated with mutations in FBN2 ${ }^{33}{ }^{34}$ - suggested this to one of us (DGFH). Marfan's syndrome was diagnosed originally: it is of interest that several authorities have suggested that Marfan's original case was actually Beal's syndrome. ${ }^{33} 34$ At birth the child was unusually long with limb curvature suggesting arthrogryposis. Walking was delayed and he never ran. At the age of seven an EMG was reported as myopathic, and muscle biopsy revealed a predominance of relatively small type 1 fibres and occasional lobulated ones, surrounded by thickened endomysium and perimysium. Immunocytochemistry for fibrillin could not be done because of the age and fixation of the tissue, nor was genetic analysis possible or further clinical details obtainable.

The pathogenesis of Marfan's syndrome is incompletely understood, but a dominant negative mechanism is proposed, with mutant fibrillin monomers impairing the function of the wild-type protein produced by the normal allele. ${ }^{35}$ The fibrillin-1 $350 \mathrm{kDa}$ glycoprotein involved has a variety of domains including multiple epidermal growth factor (EGF)like motifs. These are thought to be involved in the polymerisation of fibrillin monomers to form microfibrils, ${ }^{12}$ which surround the amorphous elastin core in elastic fibres and are scattered as bundles, associated with basement membranes, in non-elastic tissues. Microfibrils have at least two functions: load distribution during mechanical actions, and an anchoring effect between elastic fibres, cells, and basement membranes. ${ }^{12}$ In the musculoskeletal system they form an integral component of the endomysium and perimysium, where presumably both these functions are of major importance. $^{121415}$

The biomechanical effects of fibrillin act during growth as well as later in life. ${ }^{13-15}$ In the skeleton it has been postulated that fibrillin-rich microfibrils may control growth negatively by maintaining periosteal tension and exerting tensile force from ligaments and tendons. Muscle development depends on the limb mesenchyme ${ }^{36}$ and may therefore be adversely influenced by abnormalities in the matrix. Later in life, muscle structure and function are dependent on the force demanded and the stress applied: if there is unsatisfactory anchoring and an abnormal relation between extracellular matrix and muscle fibre basement membrane, these may suffer, although the precise molecular mechanisms are uncertain.

The nonsense mutation identified in this family has been reported three times before but involvement of muscle is not mentioned. ${ }^{37-39}$ We suggest that replacement of normal fibrillin by an abnormal form in the family members described here resulted in the myopathy. To our knowledge, this is the first time that abnormalities in fibrillin- 1 have been documented in muscle tissue.

The careful description by Antoine Marfan of the first case of Marfan's syndrome included mention of musculoskeletal abnormalities. This associated, previously unreported, life threatening respiratory muscle weakness shows that muscle features should be borne in mind when assessing these patients, and complaints of fatigue or dyspnoea should not be ascribed to cardiac or other disease without appropriate neuromuscular investigations.

\section{ACKNOWLEDGEMENTS}

We gratefully acknowledge the generous help of the Barclay Foundation of Glasgow University. We are also indebted to the Marfan Trust
(PC), Bluff Field Charitable Trust and St George's Hospital Medical School and NHS Trust (AHC) for their support. We thank Ian Downie BSc for his excellent technical assistance and Drs Kanti Patel, Alistair McKay, Andrew Weir, and David Marshall for access to their patients and clinical information.

\section{Authors' affiliations}

W M H Behan, Department of Pathology, Glasgow University, Glasgow, UK

C Longman, M Boxer, P Foskett, Department of Medical Genetics,

Glasgow University

R K H Petty, Department of Neurology, Glasgow University

P Comeglio, A H Child, Department of Cardiological Sciences, St

George's Hospital Medical School, London SW 17, UK

*D G F Harriman, Department of Neuropathology, Leeds University, Leeds, UK

*Retired

Competing interests: none declared

\section{REFERENCES}

1 Pyeritz RE. The Marfan syndrome. Ann Rev Med 2000,51:481-510.

2 Dietz H, Ramirez F, Sakai L. Marfan syndrome and other microfibrillar diseases. In: Harris H, Hirschhorn K, eds. Advances in human genetics, vol 22. New York: Plenum Press, 1994:153-86.

3 Pyeritz RE, McKusick VA. The Marfan syndrome: diagnosis and management. N Engl J Med 1979;300:772-7.

4 McKusick VA. The Marfan syndrome. In: Heritable disorders of connective tissue, 4th ed. St Louis: CV Mosby, 1972:61-223.

5 Beighton P, de Paepe A, Danks D, et al. International nosology of heritable disorders of connective tissue, Berlin, 1986. Am J Med Genet 1988;29:581-94.

6 De Paepe A, Devereux RB, Dietz HC, et al. Revised diagnostic criteria for the Marfan syndrome. Am J Med Genet 1996;62:417-26.

7 de Paepe A. Dural ectasia and the diagnosis of Marfan's syndrome. Lancet 1999:354:878-9.

8 Marfan AB. Un cas de déformation congénitale des quatres membres, plus prononcée aux extrémités caractérisée par l'allongement des os avec un certain degrée d'amincissement. Bull Mem Soc Med Hop (Paris) 1896;13:220-6.

9 Young ML. Arachnodactyly. Arch Dis Child 1929;4:190-209.

10 Fulcher $\mathbf{P H}$, Southworth $\mathrm{H}$. Arachnodactyly and its medical complications. Arch Intern Med 1938;61:693-703.

11 Lambie CG, Shellshear KE, Shellshear JL. Arachnodactyly or Marfan's syndrome. Med J Austr 1950;1:213-23.

12 Robinson PN, Godfrey M. The molecular genetics of Marfan syndrome and related microfibrillopathies. J Med Genet 2000;37:9-25.

13 Sakai LY, Keene DR, Engvall E. Fibrillin, a new 350 kD glycoprotein, is a component of extracellular microfibrils. J Cell Biol 1986;103:2499509.

14 Zhang H, Hu W, Ramirez F. Developmental expression of fibrillin genes suggests heterogeneity of extracellular microfibrils. J Cell Biol 1995; 129:1 165-76.

15 Gibson MA, Finnis ML, Kumaratilake JS, et al. Microfibril-associated glycoprotein-2 (MAGP-2) is specifically associated with fibrillin-containing microfibrils but exhibits more restricted patterns of tissue localisation and developmental expression than its structural relative MAGP-1. J Histochem Cytochem 1998;46:871-8.

16 Dietz HC, Cutting GR, Pyeritz RE, et al. Marfan syndrome caused by a recurrent de novo nonsense mutation in the fibrillin gene. Nature 1991;352:337-9.

17 Collod G, Babron MC, Jondeau G, et al. A second locus for Marfan syndrome maps to chromosome 3p24.2-p25. Nat Genet 1994;8:264-8.

18 Behan WMH, More IAR, Behan PO. Mitochondrial abnormalities in the postviral fatigue syndrome. Acta Neuropathol 1991;83:61-5.

19 Beesley JE. Multiple immunolabelling techniques. In: Beesley JE, ed. Immunocytochemistry. A practical approach. Oxford: Oxford University Press, 1993: 103-25.

20 Nijbroek G, Sood S, Mclntosh I, et al. Fifteen novel FBN1 mutations causing Marfan syndrome detected by heteroduplex analysis of genomic amplicons. Am J Hum Genet 1995:57:8-21.

21 Pereira L, Levran O, Ramirez, et al. A molecular approach to the stratification of cardiovascular risk in families with Marfan's syndrome. $N$ Engl J Med 1994;331:148-53.

22 McKusick VA. The Marfan syndrome. In: Heritable disorders of connective tissues, 3rd ed. St Louis: Mosby Kimpton, 1966:52.

23 Hudgson P, Gardner-Medwin D, Fulthorpe JJ, et al. Nemaline myopathy. Neurology 1967; 17:1 125-42.

24 Cunliffe WJ, Hudgson P, Fulthorpe JJ, et al. A calcitonin-secreting medullary thyroid carcinoma associated with mucosal neuromas, marfanoid features, myopathy and pigmentation. Am J Med 1970;48:120-6.

25 Goebel HH, Muller J, DeMyer W. Myopathy associated with Marfan's syndrome. Neurology 1973;23:1257-68.

26 Gross MLP, Teoh R, Legg NJ, et al. Ocular myopathy and Marfan's syndrome. A family study. J Neurol Sci 1980;46:105-12. 
27 Jadro-Santel D, Grcevic N, Dogan S, et al. Centronuclear myopathy with type 1 fibre hypotrophy and "fingerprint" inclusions associated with Marfan's syndrome. J Neurol Sci 1980;45:43-56.

28 Barrison IG, Isenberg DA, Kane SP. Arachnodactyly with unusual neuromyopathic and skeletal abnormalities. J R Soc Med 1980:73:64-8.

29 Joyce DA, Mastaglia FL, Ojeda VJ, et al. Familial myopathy associated with Marfanoid features and multicores. Aust NZ J Med 1984; 14:495-9

30 Pagès $M$, Echenne $B$, Pagès $A-M$, et al. Multicore disease and Marfan's syndrome: a case report. Eur Neurol 1985:24:170-5.

31 Eymard B, Tome FMS, Brunet $P$, et al. Marfan's syndrome and familial tomaculous neuropathy. A case of fortuitous association. Rev Neurol (Paris) 1986;142:703-5.

32 Kumar P, Gupta D, Sagar RK. A rare combination of Marfan's syndrome, rheumatic heart disease and muscular dystrophy - a case report. Indian Heart J 1994;46:351-2.

33 Hecht F, Beals RK. New syndrome of congenital contractural arachnodactyly originally described by Marfan in 1896. Pediatrics 1972:49:574-9.
34 Putnam EA, Zhang $\mathrm{H}$, Ramirez $\mathrm{F}$, et al. Fibrillin-2 (FBN2) mutations result in the Marfan-like disorder, congenital contractural arachnodactyly. Nat Genet 1995;11:456-8.

35 Dietz H, Mclntoch I, Sakai LY, et al. Four novel FBN1 mutations: significance for mutant transcript level and EGF-like domain calcium binding in the pathogenesis of Marfan syndrome. Genomics 1993; 17:468-75.

36 Hauschka SD. The embryonic origin of muscle. In: Engel AG, Franzini-Armstrong C, eds. Myology, basic and clinical, 2nd ed. New York: McGraw Hill, 1994:19.

37 Halliday D, Hutchinson S, Kettle S, et al. Molecular analysis of eight mutations in FBN1. Hum Genet 1999;105:587-97.

38 Loeys B, Nuytinck L, Delvaux I, et al. Genotype and phenotype analysis of 171 patients referred for molecular study of the fibrillin-1 gene FBN1 because of suspected Marfan syndrome. Arch Intern Med 2001;161:2447-54.

39 Matyas G, De Paepe A, Halliday D, et al. Evaluation and application of denaturing HPLC for mutation detection in Marfan syndrome: identification of 20 novel mutations and two novel polymorphisms in the FBN1 gene. Hum Mutat 2002;19:443-56.

\section{Clinical Evidence_Call for contributors}

Clinical Evidence is a regularly updated evidence based journal available worldwide both as a paper version and on the internet. Clinical Evidence needs to recruit a number of new contributors. Contributors are health care professionals or epidemiologists with experience in evidence based medicine and the ability to write in a concise and structured way.

Currently, we are interested in finding contributors with an interest in the following clinical areas:

Altitude sickness; Autism; Basal cell carcinoma; Breast feeding; Carbon monoxide poisoning; Cervical cancer; Cystic fibrosis; Ectopic pregnancy; Grief/bereavement; Halitosis; Hodgkins disease; Infectious mononucleosis (glandular fever); Kidney stones; Malignant melanoma (metastatic); Mesothelioma; Myeloma; Ovarian cyst; Pancreatitis (acute); Pancreatitis (chronic); Polymyalgia rheumatica; Post-partum haemorrhage; Pulmonary embolism; Recurrent miscarriage; Repetitive strain injury; Scoliosis; Seasonal affective disorder; Squint; Systemic lupus erythematosus; Testicular cancer; Varicocele; Viral meningitis; Vitiligo

However, we are always looking for others, so do not let this list discourage you.

Being a contributor involves:

- Appraising the results of literature searches (performed by our Information Specialists) to identify high quality evidence for inclusion in the journal.

- Writing to a highly structured template (about 2000-3000 words), using evidence from selected studies, within 6-8 weeks of receiving the literature search results.

- Working with Clinical Evidence Editors to ensure that the text meets rigorous epidemiological and style standards.

- Updating the text every eight months to incorporate new evidence.

- Expanding the topic to include new questions once every 12-18 months.

If you would like to become a contributor for Clinical Evidence or require more information about what this involves please send your contact details and a copy of your CV, clearly stating the clinical area you are interested in, to Claire Folkes (cfolkes@bmigroup.com).

\section{Call for peer reviewers}

Clinical Evidence also needs to recruit a number of new peer reviewers specifically with an interest in the clinical areas stated above, and also others related to general practice. Peer reviewers are health care professionals or epidemiologists with experience in evidence based medicine. As a peer reviewer you would be asked for your views on the clinical relevance, validity, and accessibility of specific topics within the journal, and their usefulness to the intended audience (international generalists and health care professionals, possibly with limited statistical knowledge). Topics are usually 2000-3000 words in length and we would ask you to review between 2-5 topics per year. The peer review process takes place throughout the year, and our turnaround time for each review is ideally 10-14 days.

If you are interested in becoming a peer reviewer for Clinical Evidence, please complete the peer review questionnaire at www.clinicalevidence.com or contact Claire Folkes (cfolkes@bmigroup.com). 